\title{
The Care of Older People with Dementia in Acute Hospitals
}

\section{Summary Report}

Fiona Cowdell RN, BA (Hons), MA

DProf Student, Institute of Health and Community Studies, Bournemouth University 


\section{ACKNOWLEDGEMENTS}

This research was supported by a grant from the Alzheimer's Society.

Grateful thanks are extended to all the participants who gave their time and shared their thoughts so generously, and to my supervisors Professor Kate Galvin and Dr Eloise Carr for their advice and guidance. 


\section{CONTENTS}

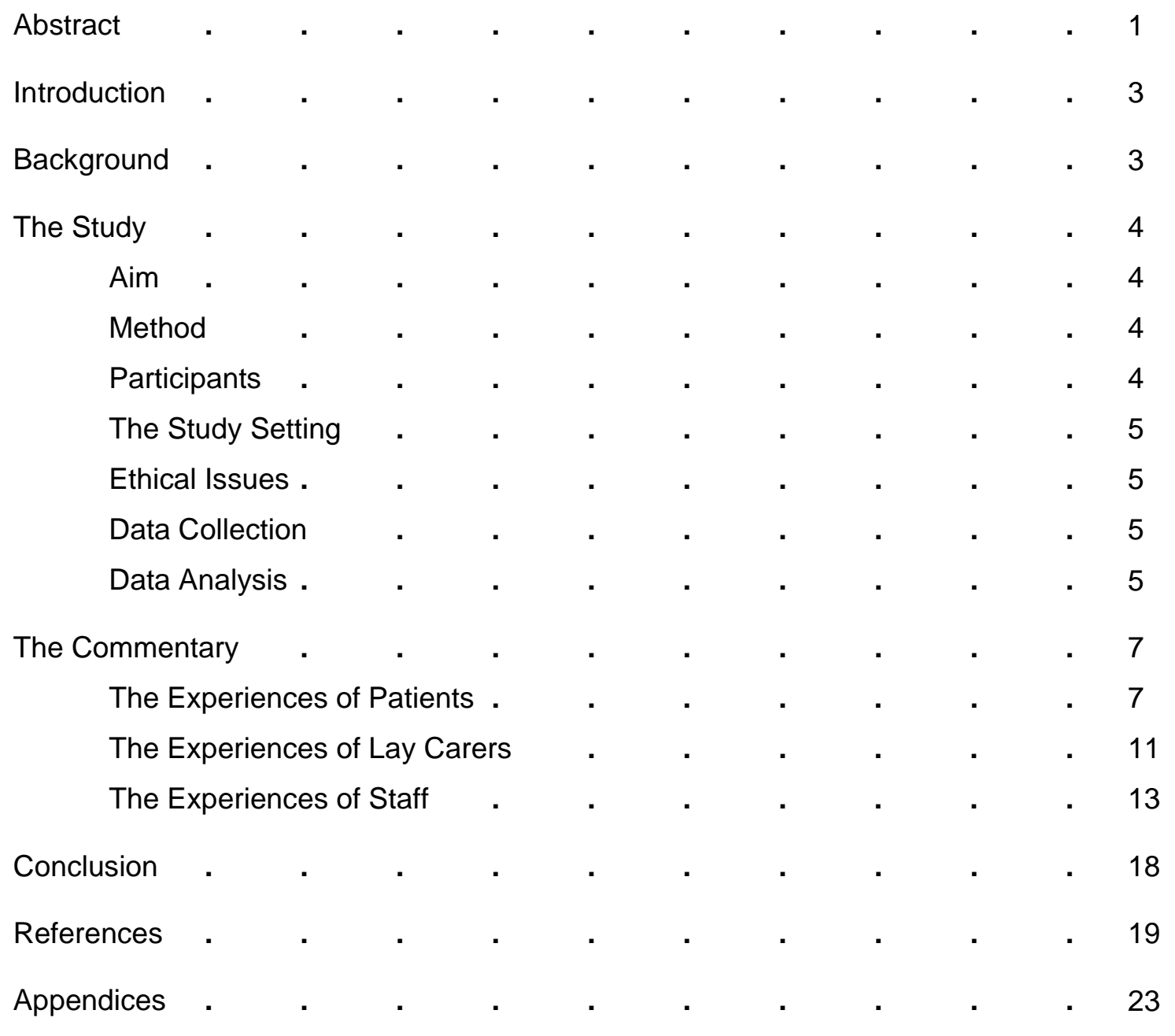





\section{ABSTRACT}

\section{Aim}

The purpose of this study was to explore the experiences of patients, lay carers and health and social care staff of the care received by older people with dementia in the acute hospital setting.

\section{Background}

The prevalence of dementia is gradually increasing as the population ages. It is estimated that by 2010 dementia will affect 840,000 people in the United Kingdom (Alzheimer's Society 2006). This increase is reflected in the rising number of older people with the condition requiring acute hospital care. Older people, classified as those over 65 years of age, occupy approximately two thirds of all hospital beds (DoH 2001). There are indications that the care these people receive is not always optimum (HAS 2000). It is suggested by Pritchard and Dewing (2001) that any deficit in care experienced by older people is compounded for people who also have dementia. At present there is a paucity of knowledge about the views of patients, lay carers and health and social care staff of the care received by people with dementia in the acute hospital setting.

\section{Method}

A critical interpretive ethnographic approach was used (Thomas 1993, Atkinson et al. 2001) with data being collected through participant observation, informal conversations and interviews. The participants included 11 older people with a documented diagnosis of dementia, 7 lay carers of patients who met the inclusion criteria and approximately 85 staff, including registered and non-registered individuals from the disciplines of nursing, allied health professions, social work and medicine. 


\section{Findings}

From the findings of this study, the patients had relatively negative feelings about being in hospital while the carers were comparatively uncritical of the service, although this finding may have been influenced by the design of the study. The staff, on the whole, attempted to deliver the best care they could, given their acknowledged lack of education and the constraints of the organisation within which they were working.

\section{Conclusion}

The experiences of patients, lay carers and health and social care staff of the care received by older people with dementia in the acute hospital setting tend to be negative. This is congruent with the current, albeit sparse, literature. In contrast to existing thoughts, the staff articulated a powerful desire to provide high quality care to this group. The study demonstrates that it is possible to actively engage older people with dementia in research, even those in the more advanced stages of the disease. There is a need to conduct further research into this subject, focusing on wards that do not specialise in the care of older people and to develop new, innovative and multi-faceted approaches to practice development that will improve the care of people with dementia in acute hospitals. 


\section{INTRODUCTION}

The prevalence of dementia is gradually increasing as the population ages (Alzheimer's Society 2006). The increase in cases of dementia is reflected in the rising number of older people with the condition requiring acute hospital care. Older people, classified as those over 65 years of age, occupy approximately two thirds of all hospital beds (DoH 2001), and there are indications that the care they receive is not always optimum (HAS 2000). It is suggested by Pritchard and Dewing (2001) that any deficit in care experienced by older people is compounded for people who also have dementia.

\section{BACKGROUND}

A literature review revealed a relative paucity of research about the care received by people with dementia in the acute hospital setting. There are two notable studies that have sought to investigate this area. Tolson et al. (1999) examined the consumers' and carers' perspective of best nursing practice for acutely ill people with coincidental dementia. It is reported that, whilst carers articulated their views, few patients actively participated; as a result the study failed to accurately explicate the patients' perspective.

Norman (2003) investigated the experiences of patients and carers of people with dementia in acute care. The study was based on adapted grounded theory methodology, and data was collected using focus groups, observation and individual interviews with patients and carers following discharge. Norman (2003) selected patients on the grounds that they had been labelled as having memory problems or dementia either by nursing staff or in the medical or nursing notes. Whilst this approach is explained, there is the potential that patients were included with memory problems caused by a variety of acute medical problems as well as by dementia. 


\title{
THE STUDY
}

\begin{abstract}
Aim
The purpose of this study was to explore the experiences of patients, lay carers and health and social care staff of the care received by older people with dementia in the acute hospital setting.
\end{abstract}

\section{Method}

A critical interpretive ethnographic approach was used (Thomas 1993, Atkinson et al. 2001). The essential tenets of this method include:

- Data being collected through extensive fieldwork and interviews (Fetterman 1998);

- The researcher being the major instrument of data collection (Coffey 1999);

- The emic perspective being considered (Keating 2001).

This method was congruent with the desire to set the research within the broader political and social context, to enable the voices of people with dementia to be heard and to produce knowledge that may be used to influence future practice.

\section{Participants}

There were three participant groups. The patient group comprised in-patients over the age of 65 who had a documented diagnosis of dementia prior to their current admission. A total of 11 patients were involved and their ages ranged from 80-94. Their latest Mini Mental State Examination (Folstein et al. 1975) score varied from 0-7/30 indicating advanced dementia. A total of seven carers whose relatives met the inclusion criteria were involved. The staff group included 85 registered and non-registered individuals from the disciplines of nursing, allied health professions, social work and medicine. 


\section{The Study Setting}

The study was undertaken on three wards in a specialist older people's unit in an acute hospital in the United Kingdom.

\section{Ethical Issues}

Ethical issues were paramount due to the vulnerability of some of the participants. Approval for the study was gained from a National Health Service Research Ethics Committee and ethical principles were applied and reviewed throughout the study.

\section{Data Collection}

The data were collected through participant observation, informal conversations and interviews. During observation, I took the role of social-participant-as-observer; that is, I took part in activities that might reasonably be expected to be part of social rather than clinical activity. This approach minimised disruption in the study setting (Rock 2001) and allowed the development of good fieldwork relationships (Germain 1993, Harrington 2003). The process of data collection involved 125 hours of participant observation over a period of a year. Field notes were recorded contemporaneously and transcribed as soon as feasible. Following an initial period of observation, key informants were identified and invited to participate in interviews. These included four lay carers, thirteen staff members and one patient. The audio taped interviews lasted for 30-60 minutes and were based on a single narrative-inducing question (Wengraf 2001). For example, staff were asked, 'Tell me your story about your involvement with [patients name]'.

\section{Data Analysis}

Data collection and analysis were iterative processes. The approach to analysis was influenced by the traditions of both critical interpretive ethnography and narrative analysis. This method was chosen to ensure that participants with dementia remained central, that equal value and credence were given to all types of data, and that fair and 
authentic accounts of the care given to people with dementia in the acute hospital setting were presented.

The analysis is based on the work of Polkinghorne (1988), Thomas (1993) and Chatterji (1998). A set of narratives using Polkinghorne's (1988) framework were constructed, which were intended to provide authentic accounts of the experiences of older people and their carers (see Appendices 1 and 2 for example narratives). The data were also analysed thematically, with the extracts of data linked to existing literature (Chatterji 1998) and set within the broader social and political milieu (Thomas 1993). The findings and discussion are linked into an overarching commentary. 


\section{THE COMMENTARY}

The first part of the commentary concerns patients and carers; the second considers the experiences of staff. Direct quotes from participants and field notes are presented in italics: underlined words are those stressed by participants, while underlined, bold words are those that were said very forcefully.

\section{The Experiences of Patients}

At present, exceptionally little is known about the experience of people with dementia in the acute hospital setting. The themes identified in this study were the experience of being in hospital, interactions with staff and uncertainty about the future.

\section{- The Experience of Being in Hospital}

When asked directly about their experience of being in hospital, a number of participants were able to express their thoughts: Ben described things as being very dark - he didn't know exactly what, but knew it was black: 'Not exactly happy is life you know...I don't know I'm not sure about it here.' Later he described his experience further: 'What happens, nothing much, but you don't expect much.' Dora said she didn't much like being in hospital: 'It gets you down, it do, it really gets yer...oh I don't know l'm sure, just before lunch I felt terrible, nobody come to you and said to you what's the matter or nothing... they didn't care, so long as they come in and you see 'em and they see you, that's all that matters.'

One issue that appeared to cause particular distress was the level of noise on the wards. Some patients found it disturbing when groups of people were speaking, especially when they were out of sight. These interactions tended to be interpreted as arguments. As two nurses talked in the corridor outside her bay, Amy said, 'I do wish they wouldn't stop arguing, would stop arguing I mean,' she laughed, realising her error. Following a relatively peaceful ward round, Dora commented, 'just before lunch there was a going on, I don't know what it was, I wasn't involved in it but they were quarrelling'. 


\section{- Interactions with Staff}

The interactions between patients and staff were dominated by the delivery of essential physical care. Dementia care can broadly be divided into two camps: the 'old culture' represents the biomedical model with an underlying philosophy of 'no cure, no hope'. The seminal work of Kitwood and Benson (1995) heralded the 'new culture' of dementia care in which the approach that other people have towards the person with dementia is believed to have a major impact on the person's experience of the condition. The focus of the 'new culture' is on preserving personhood. Kitwood (1997) suggests that personhood is undermined by negative interactions with others, which he calls malignant social psychology (MSP), and seventeen different types of MSP are delineated.

When I was observing care, episodes of MSP were regularly identified. Occasionally, several different types were seen within one brief interaction. For example, intimidation, imposition, accusation and disparagement were observed as one patient was prepared to eat his lunch:

The NA [nursing assistant] starts to give out lunches in the bay. He goes over to Walter and asks him if he wants lunch. Another assistant comes in to help get Walter out of bed. She asks him if he is going to sit up in bed or sit out in his chair for lunch. They pull the curtains round the bed and start to get Walter into his chair. They bombard him with instructions, 'sit up, sit yourself up, no, no'. It seems that Walter would prefer to stay in bed 'you can't do that, look what you've done in the bed'. Walter has been incontinent. They tell him to sit in his chair and eat his lunch. He does not look comfortable or settled, they tell him they will 'clean him up afterwards'. To add to the humiliation the curtains are pulled back and the bed stripped and remade in the middle of the bay.

It is important to note that Kitwood (1997) is clear that the term malignant does not imply that those delivering care are bad. He stresses that much care is delivered with good intention. The malign element is a result of our cultural heritage rather than any ill intent on the part of individuals. It was evident during observation that care was not delivered with ill intent but rather that it was provided without any real thought of the person as a human being. It is, of course, relatively easy to identify snapshots of MSP. This may be because in dementia care we have been conditioned to see and hear the negative. 
Whilst much of the care was delivered with kindness, it could be seen to erode the personhood of individuals. It is recognised by Ashworth and Ashworth (2003) that kindness is important but that it does not equate with affording the person respect. A lack of respect was identified where patients were not allowed to undertake tasks of which they were capable and when their communication was ignored.

She asks if he can shave himself; he says he can. She says 'are you sure, I don't want you to cut yourself'. The nursing assistant proceeds to shave Ben.

She walks with Amy and her Zimmer frame to the bathroom and starts to talk to her. Amy says 'if only it didn't hurt so much' the NA completely ignores this. Amy limps a little further towards the bathroom.

Although the intention of the nurse in not allowing him to shave himself could be construed as being in his best interests, the effect of repeated similar episodes was that Ben quite rapidly lost his ability to participate in any of his care. This phenomenon is noted by Faulkner (2001) who suggests that disempowering patients in a single task appears to have a cumulative effect to the point where people lose any desire or ability to self care. The lack of connection with patients, for example when Amy reported her pain, led, as Killick (2004) suggests, to patients withdrawing into themselves and reducing their efforts to communicate, possibly due to their frustration at not being listened to.

The aim in 'new culture' dementia care is to provide person-centred care, although as Packer (2000) states, this concept lacks a cohesive and consistent definition. A range of models attest to the centrality of the need to know the person, the necessity of communication that acknowledges the emotional or felt meaning and the requirement to work with people rather than for them (Kitwood 1997, Vittoria 1998, Cheston and Bender 2003). The need to develop two-way relationships is recognised by Norman (2006).

Episodes of person-centred care were observed during this study:

The nursing assistant helps Hilda with her menu. She gives her one menu at a time and gives her time to read them and make her choices, the nurse ticks these 
off. Hilda has a very clear view on what she likes to eat. They chat about filling in the menus and how boring it is reading them out time after time, they both laugh, the SNA gives Hilda her full attention for a moment.

Such person-centred interactions were difficult to capture, possibly because those staff who worked in this mode tended to do so consistently, making such exchanges less remarkable.

The experience of the participants indicates that the care they received was far from being person centred. Instead, their care was primarily based on ensuring that their physical needs were met. There was relatively little evidence of staff getting to know or developing relationships with patients. As Kitwood (1997) proposes, many health care staff continue to function in the I-It mode (Buber 1937), although there were examples of staff moving, albeit temporarily, to the I-Thou mode. It was rare to witness spontaneous conversation between people with dementia and staff. Generally, interactions were limited to those related to functional activities. The few episodes of communication that moved beyond specifics gave apparent pleasure to both parties. In these brief moments of authentic relationship the patients appeared to experience a fleeting nourishment of their personhood.

\section{- Uncertainty about the Future}

One concern for several patients was their feeling of great uncertainty about their future. Hilda experienced many episodes when she was unsure about the plans for her: 'I don't know how long I'm going to be here, I've been here for a while, I thought once I was back on my feet they'd send me home.' Similar uncertainly was experienced by Ben: 'Don't know what's happening to me... do I stay here forever?...People never look and they never speak, the doctors and that they come in, there's a reason for it but it's not very satisfying.' Dora regularly expressed her concern about what was going to happen to her: 'You don't know where they're going to put yer, you're never, every day, it's change which is wrong.'

These findings present rather a bleak picture of the experiences of patients who describe their time in hospital in quite negative terms. Care tended to focus on physical activities rather than the type of holistic approach that is advocated by the proponents of 
person-centredness. Although most care was delivered with kindness, this did not stop the niggling erosion of personhood through the inadvertent use of malignant social psychology. The experience of being in an acute hospital seemed to have the effect of slowly but surely diminishing the person.

\section{The Experiences of Lay Carers}

The data demonstrated that, in common with people with dementia, carers often found hospitalisation a difficult experience. Seven carers were involved in this study; three were husbands of patients, three were adult children and one was a friend. The themes that were identified from the data included the hospital experience, participation in care and the future.

\section{- The Hospital Experience}

When asked about care in hospital, carers tended to provide very broad statements: 'Well they're marvellous people here, you can't fault them at all whatsoever...they are, they're terrific' and 'I think she's getting as much care as she would if she was private, I don't see they can do any more'.

These thoughts may be attributed to the fact that these participants genuinely felt that the care was good. Equally, it was notable that some carers expressed considerable gratitude that the burden of care had been lifted from them. This release may have been sufficient to encourage the carers to take a very uncritical stance. The fact that their relatives were still in-patients may have made carers reluctant to share their thoughts candidly, believing this may impact on future care.

\section{- Participation in Care}

The extent to which carers wished to be involved in the process of caring in hospital varied greatly. The husbands appeared broadly content to step back from the caring role. They seemed relieved to allow others to take over their responsibilities. It is suggested by Andren and Elmstahl (2005) that whilst family caregivers experience both positive and negative reactions to caregiving, one of the satisfying aspects is providing best care. Redfern et al. (2002) recognise the dissatisfaction of relatives when they feel that they could deliver better care. For example, Eileen's husband experienced great 
frustration when staff appeared not to listen to or act on his advice about the best ways of caring for his wife.

'I even said in the early stages give me half an hour's notice on the telephone, I'll come down and l'll get her up, or out of bed or whatever it is.'

The involvement of lay carers in care delivery can be an area of contention. Allen (2000) suggests that it may be difficult for carers to negotiate an active role in a hospital environment that is alien to them and which tends to favour service providers. Familiarity with the hospital and its systems through previous admission enabled the carer of Doris to make it very clear from the time of admission that she expected to deliver Doris's usual care routine during her stay.

'The first day I came in they sort of said visiting time's not 'til, I said I've come in to help, to help you', I wash and do everything else here, I do exactly the same here, I don't mind cos I don't like leaving her you see.'

She was welcomed by staff who willingly helped with care whenever requested. This experience was totally different to that reported by Warner and Wexler (1998) of carers who were simply left to get on with it.

\section{- The Future}

Plans for the future occupied a considerable amount of the carers' time and thought. This was particularly the case for the three carers who eventually concluded that they would have to move their relative to a long term residential placement. As is often the case, this decision was precipitated by the health crisis that had required hospital admission (Wright 1998). The choice to seek residential placement was a cause of great anguish, in different ways, to each of the carers involved.

The transition to residential care is a major life event (Centre for Policy on Ageing 1996). Victor (1992) suggests that entry is sometimes regarded by carers as the final sign of failure. This idea certainly appeared congruent with the regrets that were expressed by the carers. The carers experienced ambivalent emotional reactions to their decisions (Dellasega and Nolan 1997) including both relief and guilt (Lewycka 1998). The 
emotional turmoil of the move to residential care was compounded by the concerns some carers expressed about the financial implications of such a move.

A number of the carers appeared to find the hospital experience difficult. They were mainly complimentary about the care given. The particular issues identified were their lack of meaningful involvement in care and emotional and financial concerns about future care.

\section{The Experiences of Staff}

This section reflects the current state of practice as observed. The themes that were generated include philosophies of caring for people with dementia, the value that staff attach to their work and the ability of staff to provide care.

\section{- Philosophies of Caring for People with Dementia}

The data suggest that many staff had clear personal philosophies about caring for people with dementia. These were often based on intrinsic beliefs rather than on any specific knowledge or education. People with dementia were clearly viewed as being different from other patients. The staff seemed particularly prone to labelling these individuals. These labels took different forms but were powerful and pervasive.

The majority of participants identified philosophies that emanated from personal values. For example, one nursing assistant explained, 'You try to give every patient the care that you'd want your relative to have I think'. Senior staff tended to use more abstract terminology which appeared to be derived from their training. One occupational therapist explained, 'I think thinking about their history gives you a lot of respect for that person and makes them become a person and not just a patient'.

Whilst staff had developed personal philosophies about caring for people with dementia, it was evident that their thoughts had also been influenced by the culture in which they were working. One example of such cultural influence was the tendency to label patients. The idea that people with dementia are labelled is well established. The participants in this study already carried the labels of being older and cognitively impaired (Adams and 
Bartlett 2003). Once admitted to hospital they were often labelled further, most frequently as 'only social' or 'difficult'.

One belief that emerged on each ward was the concept of the patient who was 'only social'. These were people with no acute physical health care needs who tended to be placed at the bottom of the hierarchy on the wards. It was observed that these patients, especially if they were relatively independent in terms of personal care, could spend many hours totally alone.

Those patients who staff found challenging risked being defined as 'difficult'. The application of these labels appeared to allow staff to mentally move these patients from the category of person-as-individual (a person who is capable of a relationship) to person-as-other (someone who is incapable of a relationship) (Malloy and Hadjistavropoulos 2004) and they therefore become merely objects of care. It was evident that some staff believed the often held view that patients with dementia are nonpeople (Ashburner et al. 2004); equally, other staff did not.

\section{- The Value that Staff Attach to their Work}

The staff suggested that caring for people with dementia in an acute hospital was viewed by others, and possibly themselves, as relatively unskilled and less prestigious than the work of other specialities. Staff questioned whether an acute hospital was an appropriate setting in which to care for people with dementia.

Most staff tended to feel that they had no particular skill in caring for people with dementia. However, a small number alluded to the idea that caring for older people demands specialist skills. Although the staff claimed little special knowledge, they demonstrated a considerable level of expertise on many occasions. For example,

Two physio assistants come and ask Anthony if he would like a walk. They bring a standing hoist and ask Anthony to sit forward so they can put the sling down his back, he doesn't respond, they ask again, he doesn't respond, they agree that it is better to leave him today. They seem to have an intuitive feeling and stop before Anthony becomes too frustrated. 
Whilst this example may initially appear to be relatively trivial, it demonstrates an ability to engage in brief but meaningful interaction that takes account of verbal and non-verbal communication. This interaction and other similar encounters were striking in that they appeared to be valued by the patients. However, they seemed to be imbued with ordinariness by the staff involved who were often unable to recognise or articulate the skills that they were using.

The idea that caring for people with dementia in acute hospitals is relatively unimportant may be influenced by a number of factors. At a societal level, dementia remains low on the agenda (Means et al. 2002). Equally, frontline paid workers are often afforded low status (Innes 2002). Caring for older people is traditionally viewed as the poor relation of health care (HAS 2000) and caring for people with dementia is often seen as mundane (Ashburner et al. 2004) and 'heavy' work (Nolan and Tolson 2000).

Given that the staff, to some extent, live within this culture it seems hardly surprising that they do not express great pride in their work. It is well documented that acute hospitals are not well placed to provide care for people with dementia (Dewing 2001, Hodkinson 2004). It is suggested that these patients are often perceived as relatively unimportant or unworthy (Pritchard and Dewing 2001) and that staff resent their presence (Marshall 1999). A senior member of medical staff expressed concerns about the care provided to this group:

'These patients just have very minimal contact with anybody while they're in hospital which is why we would all argue that it's, you know, it's not a good place for them to be.'

However, while staff acknowledged that an acute hospital was not an ideal place to care for people with dementia, the feeling of the staff towards patients seemed to be of resignation and sadness rather than resentment.

\section{- The Ability of Staff to Provide Care}

The extent to which staff felt able to provide care to people with dementia was influenced by their preparation for this role. This theme was dominated by feelings of uncertainty and a marked tendency to focus on physical care needs. 
The degree to which staff felt that they had been prepared to care for people with dementia varied considerably. The non-registered staff who delivered the majority of direct care reported having had the least preparation. The registered nursing staff also felt that they had little preparation, while the social workers and occupational therapists indicated that dementia care was an integral part of their curriculum. The concept that staff working in acute care settings are not well prepared to work with people with dementia is not new. Burgess and Page (2003) believe that acute health care staff frequently lack an adequate understanding of the needs of this group.

The staff, particularly nursing and therapy assistants, voiced concerns about their poor knowledge and expressed a desire to learn more. These individuals clearly articulated their wish to care for people with dementia as well as they could, but the focus of their care was consistently on meeting physical needs. One incident was observed on the day that Hilda was moving to a residential home. She was patently dreading this move:

Hilda returns from the bathroom with wet hair. The NA finds a hair brush and hair dryer and starts to dry Hilda's hair. Hilda raises her eyebrows to me. I would guess that she is a lady to whom a blow dry is an anathema.

The nursing assistant was insistent that Hilda should look nice and as though she had been cared for when she arrived at the home. She effectively blocked any recognition of Hilda's distress.

It is not surprising that staff tend to concentrate on the provision of physical care. The staff who were delivering direct care had been trained in the art of physical care and were therefore confident and comfortable working in this mode. The culture of the organisation also put a premium on physical care, possibly because it is clearly observable and also amenable to measurement unlike psychosocial care. It may be suggested that the concentration of staff on physical care was a way of them compensating for their lack of expertise. Staff therefore strived to give the best care they knew how within the familiar 'bed and body' framework (Gubrium 1975). Activity that fell outside this boundary caused concern and often led to feelings of uncertainty. On many occasions patients' attempts to communicate, particularly if there was any evidence of 
overt emotion, were simply ignored. This tactic is recognised by Ashworth and Ashworth (2003) who suggest that it is predominantly used to avoid conflict or aggression.

Episodes in which patients became 'difficult' generated feelings of discomfort and uncertainty about how they should be managed. For example:

A nurse helps Doris with her medication, suddenly Doris picks up her orange juice and throws it over her bed and drug chart, the nurse laughs gently, she looks acutely embarrassed and walks away.

Staff tended to have clear philosophies about the care they believed they should be providing, although this ideal was often subsumed within the culture in which they were working. Many staff did not value their work and they felt ill prepared and uncertain about caring for people with dementia.

Overall, the findings of this study present a sad picture of the care of people with dementia in the acute hospital setting. The patients have relatively negative feelings about being in hospital, although the carers were comparatively uncritical of the service. This finding may have been influenced by the design of the study, however. The staff generally attempted to deliver the best care they could given their acknowledged lack of education and the constraints of the organisation within which they were working.

When reflecting on this, it would be easy to simply attribute blame, which would usually be focused on staff for not routinely achieving the highest standards of care. This approach would be unjust and counterproductive. There is a need to conduct further research into this subject and to develop innovative and multi-faceted approaches to practice development. 


\section{CONCLUSION}

In essence, the data portrays a sobering picture of the experiences of older people with dementia in acute hospitals. It may be suggested that this finding could have been anticipated but, to date, there is little research to support this view. The value of this study is that it has successfully enabled people with dementia, even those in the more advanced stages, to express their thoughts. The study indicates that staff have a desire to provide good care but frequently lack the knowledge and skills to achieve this.

The purpose of the study, to generate new knowledge and insight that can be used to influence practice, has been achieved. There is a need continue to develop innovative methods of engaging older people with dementia in research and to undertake further studies into acute hospital care, particularly focusing on wards that do not specialise in the care of older people.

To effect real changes in practice, there is a need to disseminate the findings of this study widely to demonstrate that people with dementia have a valuable contribution to give to research which can used to influence practice development. In light of the complexity of caring for people with dementia, developments in practice need to be multi-faceted and involve staff at all levels within organisations. 


\section{REFERENCES}

Adams, T. and Bartlett, R. (2003) Constructing dementia. In Dementia Care (eds, Adams, T. and Manthorpe, J.). Arnold, London, pp. 3-21.

Allen, D. (2000) Negotiating the role of expert carers on an adult hospital ward. Sociology of Health and IIIness, 22, 149-171.

Alzheimer's Society (2006) Policy Positions http://alzheimers.org.uk/News and campaigns/Policy Watch/demography.htm (accessed 13.3.06).

Andren, S. and Elmstahl, S. (2005) Family caregivers' subjective experiences of satisfaction in dementia care: aspects of burden, subjective health and sense of coherence. Scandinavian Journal of Caring Sciences, 19, 157-168.

Ashburner, C., Meyer, J., Johnson, B. and Smith, C. (2004) Using action research to address loss of personhood in a continuing care setting. IIIness, Crisis and Loss, 12(1), 23-37.

Ashworth, A. and Ashworth, P. (2003) The lifeworld as phenomenon and as research heuristic, exemplified by a study of lifeworld of a person suffering Alzheimer's disease. Journal of Phenomenological Psychology, 34(2), 179-205.

Atkinson, P., Coffey, A., Delamont, S., Lofland, J. and Lofland, L. (2001) Handbook of Ethnography. Sage, London.

Buber, M. (1937) I and Thou. Continuum, London.

Burgess, L. and Page, S. (2003) Educating nursing staff involved in the provision of dementia care. Nursing Times, 99(46), 34-37.

Centre for Policy on Ageing (1996) A Better Home Life: A Code of Good Practice for Residential and Nursing Home Care. Centre for Policy on Ageing, London.

Chatterji, R. (1998) An ethnography of dementia. Culture, Medicine and Psychiatry, 22, 355-382.

Cheston, R. and Bender, M. (2003) Understanding Dementia: The Man with the Worried Eyes. Jessica Kingsley Publishers, London.

Coffey, A. (1999) The Ethnographic Self: Fieldwork and the Representation of Identity. Sage Publications, London.

Dellasega, C. and Nolan, M. (1997) Admission to care: facilitating role transition amongst family carers. Journal of Clinical Nursing, 6, 443-451.

Department of Health (2001) National Service Framework for Older People. Department of Health, London. 
Dewing, J. (2001) Care for older people with dementia in acute hospital settings. Nursing Older People, 13(3), 18-20.

Faulkner, M. (2001) Empowerment, disempowerment and the care of older people. Nursing Older People, 13(5), 18-20.

Fetterman, D. (1998) Ethnography. Sage, Thousand Oaks, CA.

Folstein, M., Folstein, S. and McHugh, P. (1975) 'Mini-mental state': a practical method for grading the cognitive state of patients for the clinician. Journal of Psychiatric Research, 12, 189-198.

Germain, C. (1993) Ethnography: The Method. In Nursing Research: a Qualitative Perspective (eds, Munhall, P. and Oiler Boyd, C.). National League for Nursing Press, New York, pp. 237-268.

Gubrium, J. (1975) Living and Dying at Murray Manor. St Martin's, New York.

Harrington, B. (2003) The social psychology of access in ethnographic research. Journal of Contemporary Ethnography, 32(5), 592-625.

Health Advisory Service (2000) Not Because They Are Old. Health Advisory Service, London.

Hodkinson, B. (2004) Dealing with Dementia: a Carer's Perspective. Unpublished paper. Innes, A. (2002) The social and political context of formal dementia care provision. Ageing and Society, 22, 483-499.

Keating, E. (2001) The Ethnography of Communication. In Handbook of Ethnography (eds, Atkinson, P., Coffey, A., Delamont, S., Lofland, J. and Lofland, L.). Sage, London, pp. 285-301.

Killick, J. (2004) Dementia, identity and spirituality. Journal of Religious Gerontology, 16(3-4), 59-74.

Kitwood, T. (1997) Dementia Reconsidered: The Person Comes First. Open University Press, Buckingham.

Kitwood, T. and Benson, S. (1995) The New Culture of Dementia Care. Hawker Publications, London.

Lewycka, M. (1998) Finding and Paying for Residential and Nursing Home Care. Age Concern, London.

Malloy, D. and Hadjistavropoulos, T. (2004) The problem of pain management among persons with dementia, personhood, and the ontology of relationships. Nursing Philosophy, 5, 147-159. 
Marshall, M. (1999) 'They should not really be here': people with dementia in the acute sector. Age and Ageing, 28, 9-11.

Means, R., Morbey, H. and Smith, R. (2002) From Community Care to Market Care? The Developments of Welfare Services for Older People. The Policy Press, Bristol.

Nolan, M. and Tolson, D. (2000) Gerontological nursing 1: challenges of nursing older people in acute care. British Journal of Nursing, 9(1), 39-43.

Norman, R. (2003) Acute nursing care for people with dementia. What happens when a person with dementia is admitted to hospital for acute care? University of the West of England, Bristol.

Norman, R. (2006) Observations of the experiences of people with dementia on general hospital wards. Journal of Research in Nursing, 11(5), 453-465.

Packer, T. (2000) A person-centred approach to the people who care. Journal of Dementia Care, Nov/Dec, 28-30.

Polkinghorne, D. (1988) Narrative Knowing and the Human Sciences. University of New York Press, Albany.

Pritchard, E. and Dewing, J. (2001) Older people with dementia in acute settings. Nursing Older People, 12(10), 21-25.

Redfern, S., Norman, I., Briggs, K. and Askham, J. (2002) Care at home for people with dementia: routines, control and care goals. Quality in Ageing, 3(4), 12-23.

Rock, P. (2001) Symbolic Interactionism and Ethnography. In Handbook of Ethnography (eds, Atkinson, P., Coffey, A., Delamont, S., Lofland, J. and Lofland, L.). Sage Publications, London, pp. 26-38.

Thomas, J. (1993) Doing Critical Ethnography. Sage, Newbury Park.

Tolson, D., Smith, M. and Knight, P. (1999) An investigation of the components of best nursing practice in the care of acutely ill hospitalized older patients with coincidental dementia: a multi-method design. Journal of Advanced Nursing, 30(5), 1127-1136.

Victor, C. (1992) Do we need institutional care? In Social Policy and Elderly People (eds, Laczko, F. and Victor, C.). Gower, Aldershot, pp. 161-172.

Vittoria, A. (1998) Preserving selves, identity work and dementia. Research on Aging, 20(1), 91-136.

Warner, L. and Wexler, S. (1998) Eight Hours a Day and Taken for Granted? The Princess Royal Trust for Carers, London. 
Wengraf, T. (2001) Qualitative Research Interviewing Biographic Narrative and SemiStructured Methods. Sage, London.

Wright, F. (1998) Continuing to Care. The Effect on Spouses and Children of an Older Person's Admission to a Care Home. York Publishing Services Ltd, York. 


\section{APPENDIX 1: EILEEN'S NARRATIVE}

\section{Introduction}

Eileen was admitted to hospital from home. She had just returned to her home following a brief stay in respite care where her condition had deteriorated rapidly. Eileen remained on the ward for eight weeks until she moved to a residential placement.

\section{The Person}

Eileen lives in a bungalow with her husband who is her main carer. She had been diagnosed with dementia several years ago. Her condition has gradually deteriorated over the years but since being in respite care her decline has been dramatic. On admission Eileen's mini mental state examination score is 0 . She attempts to communicate verbally but mostly only makes incomprehensible sounds, occasionally she manages to articulate her thoughts.

Eileen looks considerably younger that her eighty four years. She has thick brown hair which is clearly regularly cared for, her skin is clear with few wrinkles. Her eyes are bright and alert much of the time, Eileen rarely makes eye contact. Eileen always wears two ornate rings which look slightly incongruous with her gaudy pink hospital nightdress. Prior to her admission Eileen's husband describes her as being able to walk a few steps with assistance although he does acknowledge that it has been getting gradually more difficult for her to get out of the chair. On admission to hospital Eileen is totally immobile, she has gross leg oedema and a large pressure sore on one heel, she is physically very weak. She needs to be prompted frequently to eat and drink and often needs assistance. Eileen is doubly incontinent as she has been for sometime at home.

\section{The Cultural Context}

Eileen is nursed in a four bedded bay on an acute care of older people ward. Her bed space is very much her own as her husband has bought in a number of her own possessions including clothes, toiletries, magazines and a range of drinks and chocolates. Eileen is placed by the window, she is nursed on an air bed the position of which can be adjusted automatically. The bed has integral side rails and appears high even when lowered. Her bed looks in a perpetual state of disarray as Eileen tends to spend a lot of time tugging at and then folding the sheets and blankets. Eileen is copiously incontinent 
and her sheets frequently needed changing.

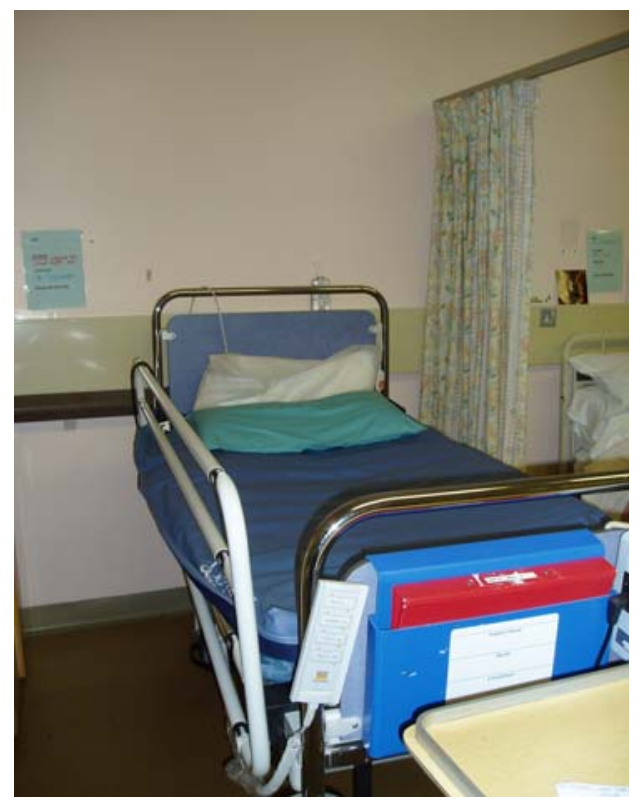

The three other ladies in the bay are extremely unwell and there is virtually no interaction between patients. Eileen's husband visits each day. He arrives the moment visiting is allowed and leaves at the last possible minute. Each day he brings in some chocolate for Eileen and often a new magazine which they sit and look at together. The white board above Eileen's bed has comprehensive instructions about her care scrawled on it in several colours.

\section{The Plan}

On admission Eileen is diagnosed with swollen legs possibly due to cardiac problems, a urinary tract infection and immobility. The plan is to treat the cardiac problems medically, to give antibiotics for the infection and to rehabilitate Eileen prior to her return home possibly with an increased package of care.

\section{The Enactment of the Plan}

It is clear that Eileen has quite complex medical problems. She is suffering with a cardiac arrhythmia and has become severely overloaded with fluid. These problems are treated with medication but are slow to respond, her treatment is regularly reviewed. Her lower legs remain swollen until discharge. Her urinary infection rapidly resolves with a course of antibiotics. It is not clear why Eileen has suddenly become so immobile, it is felt that her general weakness and swollen legs are contributing factors but do not offer a full explanation. It is suggested by some of the staff that perhaps Eileen's husband has a slightly optimistic view of her previous abilities. Her husband reports that he 'was persuaded by family and a lot of others to have a respite'. From the way he speaks it is evident that he has come to bitterly regret this decision.

As soon as Eileen's acute medical problems begin to be controlled her care focuses on trying to regain enough mobility to allow her to be cared for at home. She is assessed by a 
physiotherapist who concludes that

Eileen has some automatic functions but that she needs to be given very short instructions. The physiotherapist sees Eileen each weekday and attempts to get her to walk. Her abilities appear to be declining, a situation which her husband finds very hard to accept. He expresses his dissatisfaction with the input of the physiotherapists 'the bank holiday has come upon us and nothing really has happened the physiotherapy people are not around. I've been very concerned about that so I went to the main desk one day during this weekend and er, asked if I could talk to the physiotherapy people and they said well unfortunately they're all on bank holiday. So I am very concerned that they haven't walked her'. Her husband acknowledges that it is a bank holiday weekend but goes on to say 'but there's always something that stops it for some reason'.

The nursing staff initially try to mobilise Eileen, they follow the instructions on the board above her bed which state that she can walk up to thirty metres with two people or two people and a Zimmer frame. It states that she needs a lot of help to get from sitting to standing. The nurse's own assessments of Eileen's abilities are less positive in terms of her mobility; it also transpired that they sometimes find Eileen difficult to manage especially when she becomes aggressive. A registered nurse explains that she is waiting for three or four nurses to be available before she attempts to wash Eileen. She says that sometimes Eileen hits them particularly when people don't explain what they're doing and she gets scared. The nurse justifies having so many people saying 'might be a bit intimidating for her but it's safer for us'. Three nurses gather to wash Eileen. A nursing assistant calls loudly 'do you know how wet this lady is, she's saturated'. They stand around Eileen's bed and discuss catheterising her but decide she'd pull a catheter out. The registered nurse says 'shall we give her a bath, it would be easier we could hoist her into the bath chair'. A nursing assistant says in a baby voice 'you're going to have a nice bath Eileen'. The registered nurse returns 'we're going to bath you Eileen' to which Eileen responds 'I didn't know'. The nurse says 'you didn't know, well we're going to'. The nurse goes to touch Eileen who says 'don't, don't', the nurse explains what she needs to do and Eileen says 'it hurts, it hurts, I hurt'. The registered nurse suddenly shouts 'and up, and around', Eileen lands in the chair, she is wheeled unceremoniously to the bathroom with her nightdress just about 
covering her modesty. The registered nurse goes into the bathroom and yells at Eileen to stand 'and up' and then 'and down', Eileen sounds increasingly distressed. When her bath and hair wash are completed Eileen is wheeled back to her bedside. The nursing assistant calls to her colleague 'are we pad and panting', 'yeah' replies the registered nurse. Her pants are put on with the curtains only partly around. Despite it being a bank holiday a physiotherapist arrives to see Eileen. She goes to assist with Eileen's transfer to her chair. The nurse and physiotherapist bombard her with instructions. They are not succeeding 'come on, come on Eileen, come on, come on', Eileen yells out but eventually moves. A nursing assistant dries and styles her hair. This nurse recounts how pleased she is that Eileen has had a bath and that she now looks clean and cared for. She speculates about what Eileen used to be like, the nurse believes she must have been very polite because she said excuse me when she coughed during a meal. The nurse heard Eileen say bible so she thinks that she may have a religion, she wonders if Eileen was a teacher because she seems like someone who is used to being in authority.
The balance between encouraging mobility and safety is becoming problematic for all involved in Eileen's care. The physiotherapist has amended her whiteboard to read please $\uparrow$ frequency of walks + help with initial sit to stand, try with blue belt. The nursing staff assess Eileen prior to each transfer, sometimes she manages with two people but she generally needs a hoist. A registered nurse acknowledges that Eileen's mobility is better with her husband's guidance. Eileen does not like being hoisted. A nursing assistant arrives at Eileen's bedside with a hoist.

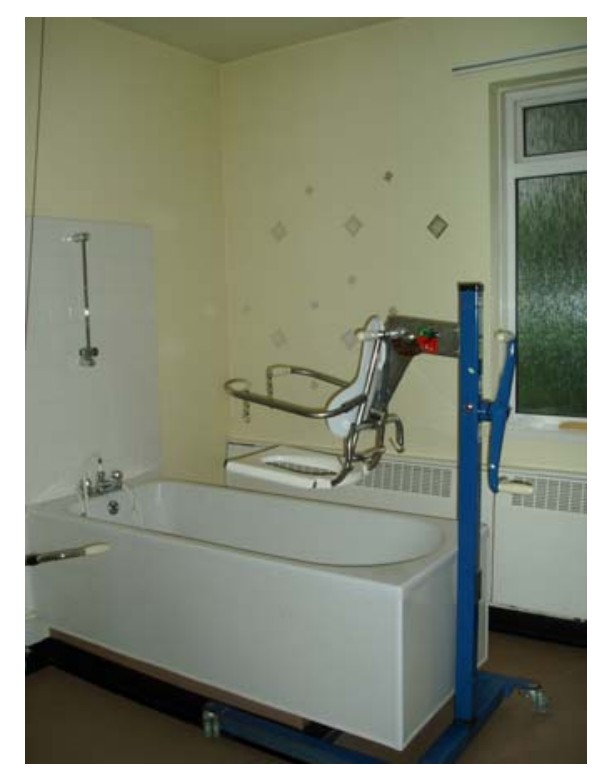

'We're just going to put you back into bed' she says in a baby voice, 'pop your hands across your chest'. They put a sling behind Eileen and move the hoist into place. 'give yourself a cuddle darling', the nurses move quickly, 'oh 
this hurts' says Eileen. The nurses laugh quietly amongst themselves although this seems unrelated to Eileen, 'oh deary dear oh dear' she says. Eileen's husband seems unsurprised that she doesn't like the hoist 'I can understand that because it's a frightening looking thing, like a small fork lift truck'. He expresses some frustration about the fact that the nursing staff seem to be using the hoist more and more and not working on Eileen's mobility. He explains 'here if she resists and even wants to bite them or whatever then they just back away, they say they're not allowed to do this or not allowed to do that. I can understand that but I feel that in the old fashioned days the sister and all the nurses would just have got hold of her firmly and done what they had to do like I have to do at home, but now they're frightened of being sued or whatever'. He says that he has found that there has been a 'resistance to getting a grip of things' and 'that they've got this attitude is quite annoying in everything they do'. He goes on to recognise other aspects of care 'otherwise I think they're wonderful. It's not a nice job or an easy job'.

The uncertainty about Eileen's future is discussed at a multidisciplinary team meeting attended by medical, nursing and therapy staff. The plan of Eileen's care appears vague, several staff report on conversations they have had with her husband, each offers a slightly different interpretation. The occupational therapist suggests that there is a need to have a clear pathway for Eileen's care as her husband and the staff need to know what they are aiming for. She says that at the moment it is not clear whether they are aiming for mobility or safe hoist transfers. The physiotherapist says that Eileen's mobility is now as good as it is going to get but that it has been suggested to her husband that it may improve once she is back in her own home. Eileen's husband has told some staff that he can only manage Eileen at home if she is mobile, others state that he wants her home regardless. He has voiced concerns about residential care 'then of course the last option is for her to go into a nursing home which I am hoping won't happen for two reasons, one is the expense of it and the other is that ..... I, I've experienced being at home on my own and it's not very nice (voice cracks)'. The conclusion of the multidisciplinary team meeting is that they should aim to discharge Eileen home with a big package of care and a hoist. The nursing and therapy staff feel that Eileen's husband is unrealistic 
about her scope for recovery but that he should be left with some hope.

The occupational therapist plans to assess Eileen's transfers and complete a site visit to her home. Following these assessments and discussions with her husband it is concluded that Eileen needs too high a level of care to return home. Eileen is referred to a social worker who finds a vacancy at a suitable residential home. Eileen's husband does not want her to go to this home, he finds one he prefers and that is nearer to their home but at present this home has no capacity to take Eileen. Eileen is rapidly transferred to the first home on the agreement that she will move to her husband's preferred location as soon as a vacancy arises. 


\section{APPENDIX 2: BEN'S NARRATIVE}

\section{Introduction}

Ben was admitted as an emergency with a chest infection and inability to cope at home. His stay in hospital lasted for approximately four weeks and ended with his transfer to a residential home.

\section{The Person}

Ben is a ninety three year old man who has been admitted primarily because he is no longer able to cope at home. His package of care to support him at home has broken down due to his increasingly challenging behaviour. He also has a chest infection. He has had several previous admissions the last being approximately five months ago. His most recent abbreviated mini mental examination score is $1 / 30$. Ben lives in his own residence and has been receiving home care three times a day seven days a week to attend to his personal hygiene, nutrition and medication needs. Ben's only family is his daughter who lives many miles away. She has a child of her own who has special needs and requires considerable care. This makes it difficult for her to visit Ben and her visits are now very infrequent.

The first time I meet Ben he is sitting in an armchair by his bed in a six bedded bay. He is wearing hospital pyjamas with the logo of the laundry service emblazoned across them; the top is green and the trousers bright orange. With his pyjamas Ben is wearing dark socks and black lace up shoes, an incongruous looking outfit. $\mathrm{He}$ is wearing large, very dirty glasses. Ben is sitting staring into space, he seems totally detached from his surroundings. He gives an immediate impression of being a quiet, private man. Ben has a bed table in front of him with a drink and some tissues on it. Beside him is a Zimmer frame. Ben's speech is virtually inaudible and he speaks only when conversation is initiated by others.

During our conversations it becomes clear that Ben is thinking about the future and what it might hold for him. He says to me 'don't know what's happening to me .... do I stay here forever ....... people never look and they never speak, the doctors and that they come in, there's a reason for it but it's not very satisfying'. When I ask Ben what it's like being on the ward he replies 'what happens, nothing much, but you don't expect much, no reference to the so called doctor'. I ask Ben if the ward is a good place to be, he tells me 'it's horrible sometimes, the feeling's 
horrible, for one thing they change their ideas'. I ask if it is difficult when people change their ideas, Ben responds 'yes, it's a bit horrifying some of these things are'. Ben appears to spend some time sitting and thinking about his future. When we first meet he talks about going home but gradually over the weeks this talk diminishes and he seems to lose sight of this goal.

Ben's capacity to meet his own activity of daily living needs is severely curtailed by both his dementia and his acute health problems. Ben is able to eat and drink independently, he does need to be prompted. Physically he is able to wash himself but does not do this unless he is guided through each stage of the process. He is consistently incontinent of urine and occasionally incontinent of faeces. Ben walks with the aid of a Zimmer frame, he has a very unsteady gait and has fallen both before and during this admission. He has no ability to take his medication as prescribed. His sleep pattern is severely disrupted and he spends much of the night awake. He communicates with difficulty especially when he is approached suddenly and with too many choices at once. When given sufficient time he is sometimes able to communicate thoughtful ideas that give some insight into what he is thinking.

\section{The Cultural Context}

Ben is in a bay with five other men all of whom look old, frail and unwell. The room feels small, gloomy and rather cramped. The view out of the window is of other hospital buildings. The four walls of the bay seem to be the limit of the patients' horizons. Ben has very few possessions with him. He uses hospital wash things, the clothes in which he was admitted remain in his locker other than his shoes. There is an absolute lack of interaction between patients on the bay, they simply do not speak to each other.

The bay is a hive of activity in the mornings as patients are helped to have a wash. Much of the therapy and medical care is delivered in the morning and the bay is visited by a group of phlebotomists. At the end of the bustle of activity in the morning the patients have lunch. After this there is a quite time and the bay often remains peaceful for the rest of the day as few patients receive many visitors.

\section{The Plan}

The plan for Ben's care is to treat his chest infection and assist him to meet his day to day activity of daily living needs. A major element of Ben's care is to expedite his discharge to a suitable setting. His chest infection responds quickly to a course of antibiotics and 
after a week he is declared medically fit for discharge.

\section{The Enactment of the Plan}

On admission Ben is unkempt and unshaven, his clothes smell strongly of urine. A nursing assistant gives Ben a bath soon after his arrival on the ward. 'I'd say once he'd had a bath and a hair wash, his nails had been done, his feet had been soaked, he had proper shoes and socks on, and clothes, the jumper with the 'kerchief ... he looked dapper, he did look dapper though, he looked lovely and when he smiled it sort of reached his eyes as

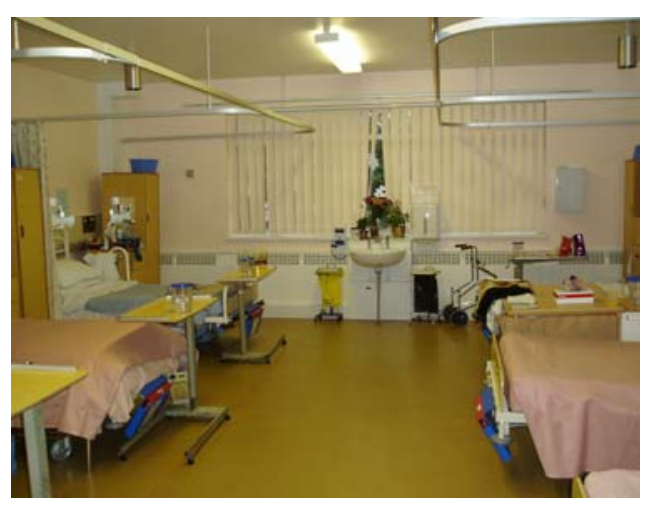
well, he was, it was a true smile he was giving you'.

Ben is helped to wash each morning. A nursing assistant gathers up Ben's wash things and some clean pyjamas, she issues a list of short instructions which Ben complies with. After a few minutes a registered nurse goes behind the curtains and asks if he can take over Ben's wash so the nursing assistant can go to coffee. The nurse reports bluntly that she "had done the bottom half but not the top'. Neither of them talks to Ben. As the registered nurse continues to wash Ben another nursing assistant and a student nurse enter the bay and walk in behind Ben's curtains. The registered nurse sends them off with a list of jobs to do in another bay. A few moments later the student nurse returns, the nursing assistant then reappears. Both go behind Ben's curtains with no warning. The patient in the next bed pulls back Ben's curtains to see what is going on. The nursing assistant tells him very sharply to stop looking. Throughout his wash Ben and the nurse both speak but don't actually respond to each other. 'You're very good at doing that' says Ben referring to the nurse tying his shoelaces, the nurse responds 'I'll just clean your glasses'. When Ben has been washed the nurse tidies up the area, checks Ben is warm enough and gives him a drink. Ben looks clean and tidy but appallingly sad and worried.

On another occasion Ben is incontinent of urine and needs to have a wash and some dry trousers. Two nursing assistants come to help him. They tut audibly as they approach him. One comments that Ben is not 'their' patient as they are working in another bay. They gather the necessary 
equipment grudgingly and pull the curtains around Ben's bed. At first they do not communicate with him at all. They begin the process giving Ben some instructions 'put your leg in, point your toes, put your foot on the floor, stand up'. These instructions are delivered rapidly one after another 'Ben stand up tall like a soldier, stand still or you'll fall over'. The task was performed quickly and mechanistically.

As Ben's physical condition improves plans for his discharge are made. Initially Ben is clear that he wants to go home, this desire appears to gradually diminish during his admission. This lessening of stated desire is the only active part that Ben plays in the discharge process.

There are several discharge meetings at which Ben is discussed. At one meeting attended by nursing staff, an occupational therapist and a care manager it is agreed that a decision needs to be made about whether or not Ben will be able to return to his own home. They agree that Ben's case should be discussed again at a forthcoming case conference which is set up when Ben's daughter returns from her holiday.

A case conference is booked for when all the involved parties are able to attend. The consultant, junior doctor, registered nurse and occupational therapist gather. The occupational therapist announces that the community psychiatric nurse is not able to attend as he is on holiday. The social work care manager arrives and reports that she had just received a telephone call from Ben's daughter saying that she will not be able to attend but that she will be available by telephone. The daughter asked if Ben is attending the case conference. The doctor says that it would be too upsetting for Ben to attend as he is not able to make a decision, everyone nods in agreement.

The meeting proceeds with each person giving their opinion about Ben's current condition and his future. The occupational therapist says that she initially felt that Ben was coping with his home circumstances but began to revise her views several days after his admission. 'The nursing staff were reporting that he was deteriorating, that he was becoming increasingly incontinent ...he'd just gone downhill and was really struggling maintaining safety on the ward let alone at home'. She reassesses him and finds that his condition has deteriorated to the point that she thinks it would distress him to repeat his cognitive assessments. She states that his community psychiatric nurse has reviewed Ben and that he has 
'always been adamant that the patient went home, and then when the CPN came in a reviewed him and said that he'd gone downhill considerably, and I knew then that my sort of inkling had been confirmed and that he wasn't coping as well as he had been when he was at home'. After extensive discussion the care manager summarises that Ben needs residential care for safety reasons. The doctor states that this decision is made for 'more than safety reasons, it is a matter of acceptable risk'.

At the end of the case conference the doctor telephones Ben's daughter, the doctor breaks the news of the decision gently expecting the daughter to say that she wants Ben to return home. The daughter says she has already been looking at homes near where she lives. They have a brief conversation in which the doctor justifies the decision, the doctor then suggests that the daughter discusses placements with the care manger. The doctor closes by saying that there is a limit of how long Ben can stay in hospital awaiting placement.

The question of how the decision to seek placement should be communicated to Ben is discussed. The doctor reports that Ben is still saying that he wants to go home from time to time. Today he asks very crossly on the ward round 'when am I going home', the doctor sidesteps the question. The occupational therapist and care manager suggest strongly that Ben should be informed, the occupational therapist states 'we need to keep him in the loop, needs to know what is going on, it is him'. They agree to go and talk to Ben and plant the idea that he will be moving on. They agree with the doctor that at this stage they will put it in terms of a temporary move to be nearer his daughter. Ben seems unmoved by the news he is given.

His daughter works closely with the care manager to find a suitable residential home. A week later she finds a home that will accept Ben. His daughter visits Ben with the care manager and tells him a little about the home, she lets the care manager do most of the talking.

Ben is transferred to a residential home a week after the case conference. A week later the home manager rings the ward to complain that Ben had a difficult transition, he is extremely disturbed and having frequent aggressive outbursts. The manager thinks he will have to move to another home as they cannot manage him. 